Homepage: http://epubs.icar.org.in/ejournal/index.php/JWR

\title{
Assessment of genetic diversity based on quality and morphological characters in spring wheat (Triticum aestivum $\mathbf{L}$ em Thell)
}

Shemshat Eyebernova, RK Sharma*, Anju M. Singh, Arvind Ahlawat and YK Kala

Division of Genetics ICAR-Indian Agricultural Research Institute, New Delhi 110012

Article History: Received: 05 March 2018, Revised: 08 May 2018, Accepted: 23 July 2018

Citation: Eyebernova S, RK Sharma, AM Singh, A Ahalavat and YK Kala. 2018. Assessment of genetic diversity based on quality and morphological characters in spring (Triticum aestivum L em Thell). Wheat and Barley Research 10(2):115-119. doi.org/ 10.25174/2249-4065/2018/78823

\section{*Corresponding author: sharma.rk.rk@gmail.com}

(C) Society for Advancement of Wheat and Barley Research

Wheat (Triticum aestivum L Em Thell) is the leading staple food crop globally which contribute about $30 \%$ of global cereal production. It is being grown in 218.5 million hectare area with an average productivity of 3.26 tonnes/ ha (FAO, 2014). Wheat has a unique property of having a storage protein called 'Gluten', which has viscoelastic nature due to which it can be processed into the large number of end products. Currently, only 15 to 18 per cent of total wheat produced in India is used by roll flour mills. Of the remaining harvested wheat less than 7 per cent goes as seed and for grain export. The remaining 76+ percent is used by the village based unorganized stone roller grinding mills to produce whole grain Atta that is used for Chapati (Nagarajan 2013). When wheat grains are grounded without the aleuron layer and seed embryo the resultant white flour is called Maida. Whole wheat is rich in gluten, a protein conglomerate that increases the elasticity of the dough. From Maida, pan bread, noodles, cakes, biscuit and pizza can be made. For every good quality product specific and adapted wheat flour is required (Nagarajan 2013).

Indian food habits are also undergoing a change in recent past from a trend of exclusive consumption of homemade food products to ready to eat convenience food products. The future wheat breeding strategies for improving the productivity and quality call upon using diverse genetic resources and to brings the desired genes not only for yield but also for quality traits in one background. Therefore, developing product specific varieties, increasing protein content and grain hardness and hectoliter weight etc to match international standards, in bread wheat are gaining focused attention of researchers. Genetic diversity of the parental line is a good indicator of performance of the progeny. Aiming to identify the genetically diverse parental lines for important quality and morphological traits among a set of genotypes this study was undertaken.

The experimental materials consisted of 64 genotypes including released and advance breeding lines developed through recombination breeding at Indian Agricultural Research Institute New Delhi and other research organizations for irrigated timely sown conditions. The material was sown at experimental farm, Division of Genetics, IARI during Rabi 2012-13 in Randomized Block Design replicated thrice. Each genotype was sown in plot having a gross area of $5 \mathrm{~m} \times 1.38 \mathrm{~m}$ with six rows at $23 \mathrm{~cm}$ spacing. To raise a healthy crop for this study recommended package of practices was used. Observations were recorded on morphological and quality characters viz., days to $50 \%$ heading, peduncle length $(\mathrm{cm})$, flag leaf length $(\mathrm{cm})$, flag leaf width $(\mathrm{cm})$, flag leaf area $(\mathrm{cm} 2)$, number of spikelets/spike, number of grains/spike, grain weight/spike (g), 1000-grain weight $(\mathrm{g})$, grain length, grain width, kernel diameter, hardness index, hectolitre weight $(\mathrm{kg} / \mathrm{hl})$ and wet and dry gluten content. The grain length and grain width were measured using an apparatus Annandrapan (by CDAC) a vision system used in rice quality. The kernel diameter and hardness index were measured by using Single Kernel Characterization System 4100 from Perten Instruments, Australia. Protein content was measured using Autokjeletch system 3100; Foss Te Cator, USA and Glutamatic instrument was used to measure the wet gluten. Mean values over the replications were used to study the divergence pattern using Mahalanobis (1936) D2 statistics. Highly significant differences among the genotypes were observed for all the 17 characters studied 
indicating considerable genetic variability present in this set of genotypes. Diversity analysis grouped 64 genotypes into nine multi-genotypic clusters using total D2 values for each character combination by non hierarchical Euclidean cluster analysis. Out of nine clusters, two clusters viz., V and IX (each with14 genotypes) together accommodated about 44 percent of genotypes (Table 1). Three cluster clusters viz. II, III and VIII consisted of two genotypes each accommodated about 9 percent of genotypes. Remaining four clusters viz., VII, I, V and VI consisted of nine, eight, seven and six genotypes respectively together accommodated 47 percent of genotypes.

The perusal of grouping of genotypes in different clusters showed that genotypes bred at different locations and zones with different parentage were grouped in one cluster. For example PBW 343 (ND/VG/9144//KAL/ BB/3/YACO'S"/4/VEE\#5'S') bred at PAU Ludhiana were grouped together with HD 2824 (PTO-1/CNO79/ PRL/GAA//HD1951) and HD 2733 (ATTILA/3/TUI/ CARC//CHEN/CHTO/4/ATTILA) bred at IARI Delhi, Karnal and IND 345 at IARI Regional Station, Indore grouped in cluster I. Similarly, HD 2967and GW 322, HI 1531, DBW 17 and UP 2338 were grouped in cluster IV. Earlier researchers like Somayajulu and group (1970) and Monu Kumar (2012) also reported the similar findings. On the contrary, several genotypes developed at one research station were found to be scattered over different clusters. Murty and Arunachalam (1966) opined that factors like heterogeneity, genetic architecture of the populations, past history of selection, developmental traits and degree of general combining ability contributes towards such type genetic diversity among the genotypes of common geographic origin.

In general, no two clusters taken together had the similar pattern for all the traits indicating wide diversity in the material for majority of traits. This distribution pattern of genotypes into clusters also suggests lack of relationship between pedigree of genotype and genetic divergence. Gartan and Mittal (2003), Sharma and Suri (2005) and Yousaf et al (2008) also reported lack of relationship between geographic distribution/pedigree and genetic divergence.

Inter $(\mathrm{D} 2)$ and intra cluster distances $(=\sqrt{ } \mathrm{D} 2)$ values were calculated for each pair of cluster which are given in Table 2. Maximum intra cluster distance (3.195) was exhibited by the cluster $\mathrm{V}$ genotypes closely followed by cluster VII (3. 194) and cluster V (3.011) while the minimum intra cluster distance was observed in cluster III (1.735). The inter cluster distance vary from minimum 3.958 to maximum 11.415. The highest interclass distance was noted between cluster VIII and II (11.415) followed by cluster III and VIII (10.201), cluster II and VII (9.924) and cluster II \& III (9.269). The distance between cluster IV and IX was found minimum (3.058) followed by cluster I and IV (3.361) and cluster VI and IX (3.422). In general, the estimates for intra cluster distances were found to be lower those of inter cluster distances suggested thereby that genotypes included within a cluster were less diverse from one another On the other hand the genotypes belonging to different clusters will be more diverse as they are separated by high statistical distances. The more diverse parents potentially be used in hybridization programme for obtaining a wide range of variability including transgressive segregants in the subsequent generations enabling further selection and improvement.

The cluster mean for each of the 17 characters was calculated by averaging the total mean values of each member belonging to that cluster (Table 3). The values of cluster means for various characters were reflections of genetic differences prevalent among the clusters and indicating a wider range of variation. Genotypes which were released for different production conditions grouped in same cluster suggesting thereby that the change in production conditions effectively changed the performance of genotypes. Out of two clusters viz., IV and IX which together had 28 genotypes, cluster IX showed desirable mean value for seed number per spike and seed weight/spike while another cluster IV showed lower mean value for protein content. Of the three clusters with least number of genotypes (2each), cluster II showed desirable mean value for grain hardness and low mean value for peduncle length, flag leaf characters, seed weight/spike, hectoliter weight, grain width, grain diameter, and 1000 grain weight. Cluster III showed desirable mean value for earliness in days to heading, and lower mean for wet and dry gluten percent. Cluster VIII showed desirable mean value for peduncle length, length, width and area of flag leaf, grain length and grain width. However, the genotypes grouped in this cluster exhibited higher mean value for days to heading and low mean value for hectoliter weight. The genotype grouped in cluster $\mathrm{V}$ exhibited higher cluster mean for wet and dry gluten content but lower mean value for grain length. Lower mean value for spikelet number per spike was observed in the genotypes grouped in cluster I. The genotypes grouped in cluster VII showed desirable mean value form grain diameter, 1000 grain weight and hectoliter weight but lower mean value for seed number per spike. The genetically diverse and promising genotypes based on per se performance for different traits were CBW 38, HS 240, QLD 33,HD 
2428, K. sona, HD 2009, HW 384, UP 2425,HD 2643 , HW588, IND 359 and HD 2824( Table 4).

Thus this study helped in grouping the 64 genotypes under study into nine multi genotypic clusters based on quality and morphological characters and identification of

Clustering pattern revealed that genetic diversity was not related either with geographical diversity or pedigree of the genotypes.

Table 1. Group constellations of 64 wheat genotypes based on Mahalanobis D2 Statistics

\begin{tabular}{ccl}
$\begin{array}{c}\text { Cluster } \\
\#\end{array}$ & $\begin{array}{c}\text { \# of } \\
\text { genotypes }\end{array}$ & Name of genotype \\
\hline I & 8 & HD 1941, HD 2329, PBW 343, HD 2204, IND 345, HD 2177, HD 2824, HD 2733 \\
II & 2 & QLD 33, HS 240 \\
III & 2 & CBW 38, K-307, \\
IV & 14 & WH 1021, C-306, HD 2888, HD 2932, HI 1531, NIAW-34, HD 2967, HD 3081, DBW \\
& & 17, HD 2851, UP 2338, HD 2009, GW 322, HD 3096 \\
V & 7 & K.sona, WH 542, VL 829, Halana, UP 2647, Atila*/STAR, HD 2687 \\
VI & 6 & Kundan, Sonalika, UP 2425, HD 2643, Vidisha, IND 338 \\
VII & 9 & UP 262, VL 616, UP 269-76, UP 2748, HUW 588, LBPV*Y-04-12, HD 2428, HD 2501 \\
VIII & 2 & HS 491, HS 490 \\
IX & 14 & HD 3059, HD 2285, HI 1592, HI 1588, HI 1598, HD 3043, PDW 621-50, IND 359, \\
& & HD 2824, HD 3076, HD 3090, HD 3070, UP2506, QLD 39 \\
\hline
\end{tabular}

Table 2. Estimate of average Intra (diagonal) and inter cluster distance for different clusters for 64 wheat genotypes

\begin{tabular}{|c|c|c|c|c|c|c|c|c|c|}
\hline Clusters & I & II & III & IV & V & VI & VII & VIII & IX \\
\hline I & 2.766 & & & & & & & & \\
\hline II & 6.461 & 2.834 & & & & & & & \\
\hline III & 4.431 & 9.269 & 1.735 & & & & & & \\
\hline IV & 3.361 & 8.137 & 4.666 & 3.011 & & & & & \\
\hline $\mathrm{V}$ & 4.568 & 5.979 & 6.389 & 4.082 & 3.195 & & & & \\
\hline VI & 4.305 & 7.667 & 6.664 & 4.245 & 3.764 & 2.979 & & & \\
\hline VII & 4.491 & 9.924 & 6.083 & 4.161 & 6.788 & 4.433 & 3.194 & & \\
\hline VIII & 8.4 & 11.415 & 10.201 & 8.21 & 8.989 & 6.229 & 6.646 & 2.368 & \\
\hline IX & 3.932 & 8.468 & 5.062 & 3.058 & 3.963 & 3.422 & 5.116 & 7.847 & 2.789 \\
\hline
\end{tabular}


Table 3. Cluster means for 64 wheat genotypes for different characters

\begin{tabular}{lccccccccc}
\hline Character/Cluster & I & II & III & IV & V & VI & VII & VIII & IX \\
\hline Days to heading & 89.25 & 97 & 73.5 & 90.43 & 92 & 92.39 & 89.42 & 95.5 & 90.32 \\
Peduncle length & 27.39 & 24.46 & 29.75 & 31.52 & 27.59 & 31.28 & 34.64 & 39.77 & 28.79 \\
Flag leaf length & 25.26 & 22.5 & 24.35 & 25.76 & 28.04 & 32.64 & 28.34 & 35.92 & 29.11 \\
Flag leaf width & 1.9 & 1.75 & 1.82 & 1.82 & 1.98 & 2.16 & 2.04 & 2.3 & 2.1 \\
Flag leaf area & 36.21 & 29.47 & 33.34 & 35.2 & 41.63 & 52.89 & 43.27 & 62.12 & 45.75 \\
Spikelets \#/spike & 18.04 & 22.65 & 18.6 & 18.86 & 20.85 & 19.83 & 16.62 & 21.42 & 19.48 \\
Seed \# per spike & 33.4 & 32.55 & 40.45 & 39.74 & 42.71 & 39.39 & 30.28 & 37.95 & 47.58 \\
Seed weight/spike & 1.19 & 0.7 & 1.5 & 1.39 & 1.33 & 1.45 & 1.3 & 1.4 & 1.81 \\
Grain Length (mm) & 7.77 & 7.57 & 7.45 & 7.5 & 7.22 & 7.77 & 8.14 & 8.55 & 7.46 \\
Grain Breadth (mm) & 2.86 & 2.57 & 2.9 & 3.16 & 2.91 & 2.98 & 3.15 & 3.24 & 3.03 \\
Grain diameter & 2.73 & 2.44 & 2.92 & 2.81 & 2.64 & 2.72 & 2.95 & 2.72 & 2.76 \\
1000 grain weight & 36.31 & 26.15 & 38.48 & 37.25 & 31.3 & 36.44 & 44.36 & 38.7 & 37.17 \\
Hardness (\%) & 85.85 & 93.33 & 88.02 & 85.16 & 91.57 & 82.19 & 77.39 & 30.71 & 85.98 \\
Hectoliter wt & 77.78 & 68.75 & 77.25 & 78.14 & 72.14 & 76.06 & 79.12 & 73.38 & 79.09 \\
Protein (\%) & 12.57 & 15.31 & 12.18 & 12.01 & 12.8 & 13.09 & 12.21 & 12.72 & 12.54 \\
Wet gluten (\%) & 3.43 & 3.84 & 3.23 & 3.79 & 4.29 & 4.28 & 4.03 & 3.9 & 3.56 \\
Dry gluten \% & 1.29 & 1.47 & 1.17 & 1.38 & 1.57 & 1.57 & 1.41 & 1.35 & 1.32 \\
\hline
\end{tabular}

Table 4. Detail of genetically divergent parental lines based on per se performance and clustering pattern for different traits

\begin{tabular}{|c|c|c|c|}
\hline $\mathrm{SN}$ & Character & $\begin{array}{c}\text { Genotype with minimum value } \\
\text { and cluster }\end{array}$ & $\begin{array}{c}\text { Genotype with maximum } \\
\text { value and cluster }\end{array}$ \\
\hline 1 & Days to heading & CBW 38 (73.30) III & HS 490 (95.5) VIII \\
\hline 2 & Peduncle length & HS $240(24.46) \mathrm{II}$ & HS 490 (39.77) VIII \\
\hline 3 & Flag leaf length & QLD 33(22.5) II & HS 490 (35.92) VIII \\
\hline 4 & Flag leaf width & HS $240(1.75) \mathrm{II}$ & HS 490 (2.3) VIII \\
\hline 5 & Flag leaf area & HS $240(29.47)$ II & HS 490 (62.12) VIII \\
\hline 6 & Spikelets/spike & PBW343 (18.04) I & QLD 33(22.65) II \\
\hline 7 & Seed number per spike & HD 2428(30.28) VII & HD $2824(47 / 98)$ IX \\
\hline 8 & Seed weight per spike & QLD 33 (0.7) II & IND 359 (1.81) IX \\
\hline 9 & Grain length (mm) & KALYAN SONA (7.22) V & HS 490 (8.55) VIII \\
\hline 10 & Grain width $(\mathrm{mm})$ & QLD 33 (2.57) II & HS 490 (3.24) VIII \\
\hline 11 & Grain diameter & QLD 33 (2.44) II & HUW 588 (2.95) \\
\hline 12 & 1000 grain weight & QLD 33 (26.15) II & HUW 588 (44.36)VII \\
\hline 13 & Hardness $(\%)$ & LBPV*Y-04-12 (30.71) VIII & HS 240 (93.33) II \\
\hline 14 & Hectoliter weight & QL D33 (68.75) II & HD 2177 (82.0) I \\
\hline 15 & Protein $(\%)$ & HD 2009(12.01) IV & HD 2643 (15.31) II \\
\hline 16 & Wet gluten $(\%)$ & HW 384 (3.23) III & UP 2643(4.29) V \\
\hline 17 & Dry gluten $(\%)$ & CBW 38(1.17) I & UP 2425 (1.57) VI \\
\hline
\end{tabular}




\section{References}

1. Gartan SL and RK Mittal. 2003. Genetic divergence in wheat. Crop Improvement 30: 85-188.

2. Mahalanobis PC .1936. On generalized distance in statistics. Proceedings of National Institute Science. India 2: 49-55

3. Monu Kumar. 2012. Genetic diversity for terminal heat tolerance in bread wheat. Unpub. M.Sc. Thesis. IARI, New Delhi

4. Murty BR and Arunachalam V. 1966. The nature of genetic divergence in relation to plant breeding system to crop plants. Indian Joournal of Genetics. 26A: 188-198
5. Nagarajan S.2013. Bio-processing of wheat -untapped opportunities for value added products. Journal of Wheat Research. 5:1-6

6. Somaayajulu PLN, Joshi AB and Murty BR .1970. Genetic divergence in wheat. Indian Journal of Genetics. 30:47-50

7. Sharma SC and Suri Vishal. 2005. Genetic diversity in relation to geographical origin/pedigree in wheat. Crop Imrovement. 32:14-19

8. Yousaf AA, Javed Akhter and Zahid LP. 2008. Genetic variability and diversity studies in wheat (Triticum aestivum L) germplasm. Pakistan Journal of Botany 40: 2087-2097. 